\title{
IMPACT OF COVID-19 ON PEDIATRIC OUT-OF-HOSPITAL CARDIAC ARREST IN THE MASOVIAN REGION
}

\author{
Jaroslaw Meyer-Szary ${ }^{1}{ }^{\oplus}$, Milosz J. Jaguszewski ${ }^{2}{ }^{\circledR}$, Jacek Smereka $^{3,4}{ }^{\oplus}$, Aleksandra Gasecka $^{5}{ }^{\circ}$, \\ Mohamed S. Emam ${ }^{5}$, Ivo John ${ }^{5}{ }^{\circ}$, Zubaid Rafique ${ }^{6}{ }^{(}$, Frank W. Peacock $^{6}$, Francesco Chirico ${ }^{7,8}{ }^{\infty}$, \\ Dorota Sagan $^{9}$ (D, Marta Jachowicz ${ }^{9}$, Lukasz Szarpak ${ }^{4,10,11^{\text {(B) }}}$ \\ 'Department of Paediatric Cardiology and Congenital Heart Diseases, Medical University of Gdansk, Poland \\ ${ }^{2} 1$ st Department of Cardiology, Medical University of Gdansk, Poland \\ ${ }^{3}$ Department of Emergency Medical Service, Wroclaw Medical University, Wroclaw, Poland \\ ${ }^{4}$ Polish Society of Disaster Medicine, Warsaw, Poland \\ ${ }^{5}$ 1st Chair and Department of Cardiology, Medical University of Warsaw, Poland \\ ${ }^{6}$ Henry JN Taub Department of Emergency Medicine, Baylor College of Medicine Houston, Texas, USA \\ ${ }^{7}$ Post-graduate School of Occupational Health, Università Cattolica del Sacro Cuore, Rome, Italy \\ ${ }^{8}$ Health Service Department, Italian State Police, Milan, Italy \\ ${ }^{9}$ Students Research Club, Maria Sklodowska-Curie Medical Academy in Warsaw, Poland \\ ${ }^{10}$ Institute of Outcomes Research; Maria Sklodowska-Curie Medical Academy in Warsaw, Poland \\ ${ }^{11}$ Research Unit, Maria Sklodowska-Curie Bialystok Oncology Center, Bialystok, Poland
}

KEY WORDS: out-of-hospital cardiac arrest, OHCA, pediatric, SARS-CoV-2, COVID-19

Disaster Emerg Med J 2021; 6(4): 183-185

To the Editor,

the epidemiology of pediatric out-of-hospital cardiac arrest (OHCA) is reasonably well described [1-6], with annual occurrence rates estimated at 7-8 per 100000 children [7], although extensive variation exists, ranging from 2.28 to 18.0 per 100000 person-years [5, 8-12], depending on the location and timing of the study. Data on pediatric OHCA during COVID-19 pandemic are very limited. Our purpose was to examine the changes in the characteristics and survival outcomes of pediatric OHCA following the COVID-19 outbreak in the Masovian region (Poland).

We conducted a retrospective cohort study from a National Emergency Medical Service Command Support System which is a prospective registry of medical interventions performed by emergency medical services (EMS) in Poland [13]. Our study was conducted according to the STROBE (strengthening the reporting of observational studies in epidemiology) guidelines [14] and complies with the Declaration of Helsinki. The study protocol was approved by the Institutional Review Board of the Polish Society of Disaster Medicine (approval no. 01.03.21.IRB).
All eligible consecutive pediatric patients suffering an OHCA from March 1 to December 30 in the years 2019 (pre-pandemic period) and 2020 (pandemic period), were enrolled. Children eligible for inclusion were $>48$ hours and $<18$ years of age and suffered an OHCA with pediatric advanced life support implementation by EMS teams. Subjects were excluded if the information on gender or cardiopulmonary resuscitation outcomes was missing. The pediatric population count was based on the Polish Central Statistical Office report for the year 2019. The outcomes included before-and-after comparative analyses focusing on the COVID-19 outbreak period and the analogous period in 2019. Statistical analysis was performed using STATA version 16.1EN (StataCorp LLC, Texas, USA).

There were 1091319 children living in the analyzed region in 2019. Since data for 2020 were not available, it was assumed there was no substantial change in the population during the study period. Overall, a total of 47 pediatric OHCA patients were included in this analysis [mean age 6.1 (6.3) years, $59.6 \%$ males; 18 in pre-COVID-19 and 29 in the

ADDRESS FOR CORRESPONDENCE:

Lukasz Szarpak, Maria Sklodowska-Curie Medical Academy in Warsaw e-mail: lukasz.szarpak@gmail.com

This article is available in open access under Creative Common Attribution-Non-Commercial-No Derivatives 4.0 International (CC BY-NC-ND 4.0) license, allowing to download articles and share them with others as long as they credit the authors and the publisher, but without permission to change them in any way or use them commercially. 


\begin{tabular}{|c|c|c|c|c|}
\hline Variable & Pre-COVID-19 (2019) & COVID-19 (2020) & Difference $(95 \% \mathrm{Cl})^{*}$ & $p$-value \\
\hline$n$ & 18 & 29 & & 0.10 \\
\hline n per 100.000 & 1.65 & 2.66 & & 0.10 \\
\hline Males (\%) & $13(72.2 \%)$ & $15(51.7 \%)$ & $-0.22(-0.49,0.05)$ & 0.11 \\
\hline Age, years (SD) & $5.1(6.5)$ & $6.7(6.2)$ & $1.60(-2.16,5.36)$ & 0.40 \\
\hline EMS arrival time, min (SD) & $11.2 \pm 5.4$ & $9.9 \pm 4.2$ & $-1.30(-4.23,1.63)$ & 0.38 \\
\hline $\begin{array}{l}\text { OHCA cause } \\
\text { Medical } \\
\text { Trauma }\end{array}$ & $\begin{array}{c}17(94.4 \%) \\
1(5.6 \%)\end{array}$ & $\begin{array}{c}24(82.8 \%) \\
5(17.2 \%)\end{array}$ & $\begin{array}{c}0.56(0.10,3.26) \\
3.75(0.40,34.96)\end{array}$ & $\begin{array}{l}0.52 \\
0.25\end{array}$ \\
\hline $\begin{array}{l}\text { Presenting rhythm, n (\%) } \\
\text { Shockable } \\
\text { Not shockable }\end{array}$ & $\begin{array}{c}1(5.6 \%) \\
17(94.4 \%)\end{array}$ & $\begin{array}{c}1(3.4 \%) \\
28(96.6 \%) \\
\end{array}$ & $\begin{array}{l}0.64(0.04,10.94) \\
1.65(0.10,28.09)\end{array}$ & $\begin{array}{l}0.76 \\
0.73\end{array}$ \\
\hline Adrenaline administered, n (\%) & $8(42.1 \%)$ & $14(48.3 \%)$ & $1.17(0.36,3.80)$ & 0.80 \\
\hline Atropine administered, n (\%) & $2(11.1 \%)$ & $3(10.3 \%)$ & $0.92(0.14,6.14)$ & 0.93 \\
\hline Amiodarone administered, n (\%) & $0(0.0 \%)$ & $2(6.9 \%)$ & $3.36(0.15,74.15)$ & 0.44 \\
\hline $\begin{array}{l}\text { Airway management, n (\%) } \\
\text { Supraglottic airway device } \\
\text { Endotracheal tube }\end{array}$ & $\begin{array}{l}8(44.4 \%) \\
4(22.2 \%)\end{array}$ & $\begin{array}{c}6(20.7 \%) \\
16(55.2 \%) \\
\end{array}$ & $\begin{array}{c}0.33(0.09,1.19) \\
4.31(1.14,16.30)\end{array}$ & $\begin{array}{l}0.09 \\
0.03\end{array}$ \\
\hline Intraosseous access, n (\%) & $7(38.9 \%)$ & $1(3.4 \%)$ & $0.06(0.01,0.51)$ & 0.01 \\
\hline $\begin{array}{l}\text { Outcome, } \mathrm{n}(\%) \\
\text { Death in the field } \\
\text { Transported with ongoing CPR } \\
\text { Transported with ROSC }\end{array}$ & $\begin{array}{l}6(33.3 \%) \\
5(27.8 \%) \\
8(44.4 \%)\end{array}$ & $\begin{array}{c}10(34.5 \%) \\
13(44.8 \%) \\
6(20.7 \%)\end{array}$ & $\begin{array}{l}1.05(0.30,3.65) \\
2.11(0.60,7.48) \\
0.33(0.09,1.19)\end{array}$ & $\begin{array}{l}0.94 \\
0.25 \\
0.09\end{array}$ \\
\hline
\end{tabular}

COVID-19 periods]. Patient characteristics, OHCA cause, and the presenting rhythm (either unshockable or not) were similar in the pre-COVID-19 and COVID-19 periods (Tab. 1). Time to EMS arrival and EMS interventions were similar with regard to the medical therapy administered (the rates of adrenaline, atropine, and amiodarone administered). However, children with OHCA in the COVID-19 period more often received an endotracheal tube compared to the pre-COVID-19 period ( $p=0.03$ ), although the use of a supraglottic airway device did not change. The use of intraosseous access decreased during the COVID-19 period ( $p=0.01$ ). The outcomes were similar in the categories of 'death in the field', 'transported with ongoing CPR', and 'transported with ROSC', although numerically more patients were transported with ongoing $C P R$, and much fewer did not have ROSC.

To conclude, we found no significant changes regarding outcomes, demographics, and field resuscitation rates, although we did find a marked increase in the rate of endotracheal tube intubation. Our findings may be due to the overall poor outcomes that occur with pediatric OHCA or relatively small sample size, but we did not observe a negative 'COVID-19 effect' on outcomes in pediatric OHCA. Of note, the number of pediatric OHCA was higher during COVID-19 period, with a marked increase in traumatic OHCA. While this may not be a direct effect of COVID-19 infection in the pediatric population, it may be related to limited access to healthcare, increased psychosocial stress, and exposure to domestic violence. Although the number of cases of traumatic $\mathrm{OHCA}$ is limited, the relative rise in cases over a year is further investigation. A similar analysis in other regions and countries will distinguish between an alarming trend and an anomalous data point.

As a retrospective evaluation of the previously collected data, our paper is limited to hypothesis generation. Further, as pediatric OHCA is a relatively uncommon event, our sample size is small which limits our conclusions. Finally, because no COVID-19 testing results were recorded, we cannot confirm if any of the cases of OHCA were related to COVID-19.

Altogether, pediatric OHCA in the Masovian region is not common and has a poor prognosis. 
The COVID-19 pandemic may have increased the number of OHCA, but has not changed the patient characteristics, presenting rhythm, or outcomes. Larger studies are needed to elucidate the trends noted here.

\section{Conflict of interest}

All authors declare no conflict of interest.

\section{REFERENCES}

1. Johnson MA, Grahan BJH, Haukoos JS, et al. Demographics, bystander CPR, and AED use in out-of-hospital pediatric arrests. Resuscitation. 2014; 85(7): 920-926, doi: 10.1016/j.resuscitation.2014.03.044, indexed in Pubmed: 24681302.

2. Okamoto $Y$, Iwami T, Kitamura T, et al. Regional variation in survival following pediatric out-of-hospital cardiac arrest. Circ J. 2013; 77(10): 2596-2603, doi: 10.1253/circj.cj-12-1604, indexed in Pubmed: 23823852.

3. Foltin GL, Richmond N, Treiber M, et al. Pediatric prehospital evaluation of NYC respiratory arrest survival (PHENYCS). Pediatr Emerg Care. 2012; 28(9): 859-863, doi: 10.1097/PEC.0b013e3182675b61, indexed in Pubmed: 22929130.

4. Moler FW, Donaldson AE, Meert K, et al. Pediatric Emergency Care Applied Research Network, Pediatric Emergency Care Applied Research Network. In-hospital versus out-of-hospital pediatric cardiac arrest: a multicenter cohort study. Crit Care Med. 2009; 37(7): 2259-2267, doi: 10.1097/CCM.0b013e3181a00a6a, indexed in Pubmed: 19455024.

5. Atkins DL, Everson-Stewart S, Sears GK, et al. Resuscitation Outcomes Consortium Investigators. Epidemiology and outcomes from out-of-hospital cardiac arrest in children: the Resuscitation Outcomes Consortium Epistry-Cardiac Arrest. Circulation. 2009; 119(11): 1484-1491, doi: 10.1161/CIRCULATIONAHA.108.802678, indexed in Pubmed: 19273724.

6. Donoghue AJ, Nadkarni V, Berg RA, et al. CanAm Pediatric Cardiac Arrest Investigators. Out-of-hospital pediatric cardiac arrest: an epidemi- ologic review and assessment of current knowledge. Ann Emerg Med. 2005; 46(6): 512-522, doi: 10.1016/j.annemergmed.2005.05.028, indexed in Pubmed: 16308066.

7. Meert KL, Telford R, Holubkov $R$, et al. Therapeutic Hypothermia after Pediatric Cardiac Arrest (THAPCA) Trial Investigators. Pediatric Out-of-Hospital Cardiac Arrest Characteristics and Their Association With Survival and Neurobehavioral Outcome. Pediatr Crit Care Med. 2016; 17(12): e543-e550, doi: 10.1097/PCC.0000000000000969, indexed in Pubmed: 27679965.

8. Law AKK, Ng MH, Hon KL, et al. Out-of-Hospital Cardiac Arrest in the Pediatric Population in Hong Kong: A 10-Year Review at a University Hospital. Pediatr Emerg Care. 2018; 34(3): 179-184, doi: 10.1097/ PEC.0000000000000661, indexed in Pubmed: 26760831.

9. Sirbaugh P, Pepe P, Shook J, et al. A Prospective, Population-Based Study of the Demographics, Epidemiology, Management, and Outcome of Out-of-Hospital Pediatric Cardiopulmonary Arrest. Annals of Emergency Medicine. 1999; 33(2): 174-184, doi: 10.1016/s0196-0644(99)70391-4.

10. Kuisma M, Suominen P, Korpela R. Paediatric out-of-hospital cardiac arrests - epidemiology and outcome. Resuscitation. 1995; 30(2): 141-150, doi: 10.1016/0300-9572(95)00888-z.

11. Ong MEH, Osmond MH, Gerein R, et al. OPALS study group. Comparing pre-hospital clinical diagnosis of pediatric out-of-hospital cardiac arrest with etiology by coroner's diagnosis. Resuscitation. 2007; 72(1): 26-34, doi: 10.1016/j.resuscitation.2006.05.024, indexed in Pubmed: 17101206.

12. Broides, A., Sofer, S. \& Press, J. Outcome of "out of hospital" cardiopulmonary arrest in children admitted to the emergency room. Isr Med Assoc J. 2000; 2: 672-674.

13. Borkowska MJ, Jaguszewski MJ, Koda M, et al. Impact of Coronavirus Disease 2019 on Out-of-Hospital Cardiac Arrest Survival Rate: A Systematic Review with Meta-Analysis. J Clin Med. 2021; 10(6), doi: 10.3390/jcm10061209, indexed in Pubmed: 33803944.

14. Elm Ev, Altman D, Egger $M$, et al. The Strengthening the Reporting of Observational Studies in Epidemiology (STROBE) Statement: Guidelines for reporting observational studies. International Journal of Surgery. 2014; 12(12): 1495-1499, doi: 10.1016/j. ijsu.2014.07.013. 